\title{
—米 \\ ENTRE O SERTÃO E O CERRADO: PARALELISMOS E DISPARIDADES
}

ANA ROSA MARQUES*

MARIA BUENO FERNANDES**

Resumo: Este trabalho aborda aspectos do universo cultural das populações que habitam o sertão sul do estado do Maranhão, bem como sua relação com a natureza. Apresenta o sertanejo que realiza sua ligação com o mundo por meio da roça para subsistência, da extração de recursos naturais do cerrado e da criação de gado sua territorialidade impressa na paisagem por meio da cultura e da convivência com o ambiente. O sertanejo revela-se como inspiração para outro modelo de desenvolvimento, pautado no uso racional dos recursos. Aborda a autonomia desses povos que vivem há mais de um século nesta região. Trata-se de uma pesquisa de abordagem qualitativa. Espera-se contribuir com o conhecimento e a valorização dessa cultura.

Palavras-chave: Território; Territorialidades; Cultura Sertaneja; Cerrado; Sertão.

Introdução

0 objetivo principal deste trabalho é expor mais de perto o universo cultural e ambiental das populações que habitam 0 sul do estado do $M$ aranhão, a partir de dados coletados na pesquisa: "As comunidades sertanejas da área de abrangência do Parque Nacional da Chapada das M esas e a sua inter ação com 0 bioma Cerrado: entre o cotidiano vivido e experienciado em suas dimensões sócioculturais e ambientais", realizada entre 2012 e 2014, na área do Parque Nacional da Chapada das Mesas (PNCM), sul do Estado do Maranhão, município de Carolina e adjacências. Nosso intuito é documentar esse modo de vida de forma a valorizar esse grupo de população tradicional para sua inserção no âmbito das 
discussões sobre as políticas públicas para essa área..

Nessa pesquisa, pudemos perceber diversas formas de viver de uma população que habita o que, hoje, é uma U nidade de Conservação de proteção integral. Essas formas de vida têm como característica em comum a forte ligação com o território: 0 sertão da chapada. Assim, enveredamos nesse universo social, cultural econômico e político de forma a compreender os laços, os fazeres, os saberes, as crenças, os valores simbólicos, enfim, os elementos constitutivos daquele grupo humano, forjados a partir de sua relação com aquela paisagem, aquele território, aquela realidade social. Acreditamos, como nos ensina $M$ assey (2015), que o espaço é uma possibilidade aberta e, portanto, abarca forte componente político. Assim, entendemos que, ao tratar mos deste espaço na perspectiva da coexistência de distintas e heterogêneas trajetórias, podemos traçar algumas características desse universo cultural do sertanejo dessa região.

0 trabalho de investigação científica como um todo ocorreu por meio de análise predominantemente qualitativa, ou seja, "partilha densa com pessoas, fatos e locais que constituem objetos de pesquisa, para extrair desse convívio os significados visíveis e latentes que somente são perceptíveis a uma atenção sensível." (CHIZZOT TI, 2003, p. 221) Cabe salientar que todo dado e todo fato aqui apresentados já são interpretações, nossas interpretações.

Este trabalho de investigação ocorreu no período de 2012 a 2014, quando foram realizadas três viagens a campo para coleta de dados e vivência com as comunidades sertanejas da área de abrangência do Parque Nacional da Chapada das Mesas (PNCM), para que tivéssemos contato mais direto com 0 cotidiano dessas populações.

A explicitação da metodologia da pesquisa não traduz, entretanto, a metodologia que utilizaremos neste trabalho. Aqui, trabalharemos com a narração, tendo em vista que, como nos ensina Larossa (1995, p. 11), "los seres humanos somos organismos contadores de historias, organismos que, individual y socialmente, vivimos vidas relatadas". Assim, em diferentes partes deste trabalho, nossa voz, nossa gramática, nossa descoberta, em diálogo com o outro, com a alteridade deste outro sertanejo que nos fala, nos ensina, nos escuta e nos transforma.

Este artigo subdivide-se em três partes. A primeira traz o histórico da ocupação da região da Chapada das M esas, considerando que contextualizar 0 universo dessa pesquisa é primordial para a compreensão alargada dessa região.A segunda apresenta o sertão e o sertanejo 
com as suas formas de viver e a convivência com o Cerrado. Já a terceira parte discute 0 território e a territorialidade e os conflitos socioambientais que se apresentam neste momento devido às transformações em seu espaço comunitário, pondo em risco 0 bioma cerrado e, consequentemente, a cultura sertaneja da Chapada das M esas. As considerações finais propõem a síntese possível das reflexões construídas até 0 presente momento.

Contexto histórico da ocupação das Chapadas das M esas

A historiografia é feita de escolhas, como tão bem nos ensina Certeau (1982). A decisão sobre o que lançar luz, ou o que eclipsar, o que narrar e como, é uma escolha do pesquisador. Assim, assumimos esse papel e deixamos claro que esta não é uma historiografia clássica, mas um recorte para retratar nossos estudos e reflexões. Sabemos que, ao selecionar o que apresentar e o que discutir, já aderimos a um pressuposto teórico-metodológico. D esse modo, escolhemos falar da presença de indígenas Timbira na região e de frentes agropastoris, que adentram 0 território do $\mathrm{M}$ aranhão a partir do início do século $X I X^{1}$, grupo populacional advindo de diferentes partes do nordeste, em especial Bahia e Pernambuco, acompanhando a expansão da atividade ganadeira, a chamada "colonização do

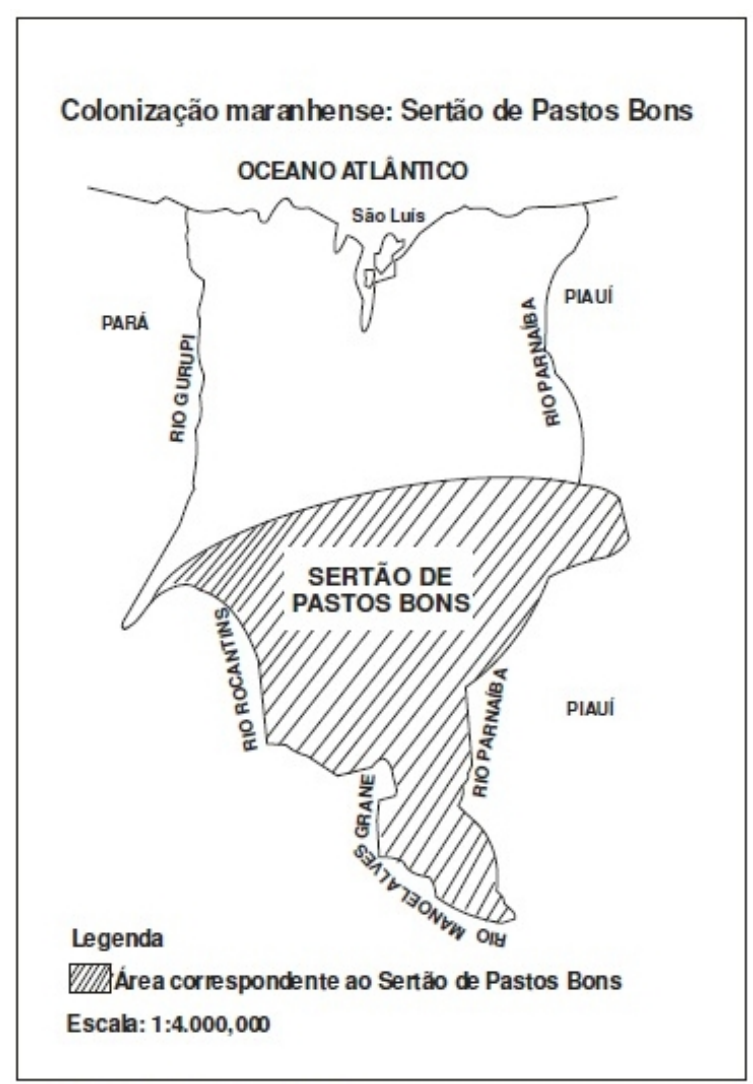

Figura 1: Colonização maranhense a partir da penetração da frente agropastoril. Fonte: (CABRAL, 1990).

gado" que se apoia na presença dos "pastos bons" na região (F igura 1 ).

Essa denominação de "pastos bons" é, segundo Carlota Carvalho (2006), atribuída devido à "beleza dos campos, suavidade do clima, superabundância das nascentes de águas correntes e perenes e à grande quantidade de frutas naturais do país" (CARVALHO, 2006, p. 96). Importante destacar que essa visão de sertão, expressa por Carvalho, destaca 
profundamente um outro sertão, descrito por Cunha (1995), que aborda o sertão da Bahia, região do semiárido brasileiro, com uma vegetação "triste, desolada, calcinada pelo sol" (CARVALH 0, 2006, 131).

Ainda sobre o tema da penetração ao interior, cabe destacar que o livro "Caminhos do gado: conquista e ocupação do sul do M aranhão", de Maria Socorro Cabral (2008), aborda-o de forma bastante ampla, como também é feito em artigo resultante dessa pesquisa, publicado por Gomes \& Fernandes (2014), intitulado: Sertão: L ócus M editer raneus.

0 encontro entre as populações indígenas e a população que penetra 0 interior a partir das frentes de expansão pastoris é repleto de conflitos. M uitos autores (RIBEIRO, 2002; T ROVÃO, 2008) atestam 0 impacto nessas populações indígenas, que, no confronto, são mortas ou expulsas do território. Entretanto, nesse processo, ocorre intensa troca cultural que resultou em uma ressignificação dos modos de produção por parte desses novos ocupantes da terra - os sertanejos do cerrado.

Desse modo, , 0 emprego de técnicas de plantio itinerante via roça no toco, o manejo da caça, utilização de espécies nativas do cerrado, que possibilitaram uma melhor convivência com esse ambiente, assim como a utilização de redes para dormir elaboradas com fibras das espécies locais, a presença do pilão, a forma de fazer a farinha, as práticas extrativistas, o reconhecimento e uso das plantas medicinais são resultados desse "encontro". Nesse sentido, corroboramos a afirmação de Porto Gonçalves (2008, p. 121): "o conhecimento dos povos indígenas do tronco $M$ acro Jê se transmitiu, em grande parte, para a 'sociedade sertaneja' que se alojou nos cerrados".

Marques \& Amorim (2014) afirmam que essas relações de convivência com 0 ambiente e adaptações pela necessidade de sobrevivência perduraram intensivamente até a década de 1950, com a fixação desses camponeses em áreas categorizadas por Andrade (2008, p.61) como "as faixas de terra entre uma e outra fazenda de gado, cuja propriedade não era reivindicada por nenhum fazendeiro." N ela permaneceram como agregados cultivando a terra sem pagar aluguel, em al guns casos, até o presente. Esse modo de vida em terra de "Nação", como é denominado, é comumente considerado posse, uma herança ancestral e sem legitimidade perante os registros em cartório.

Estas relações fundiárias foram se estabelecendo em um tempo de permanência mais lento até a chegada de uma nova frente de expansão, provocada pela construção da estrada Belém-Brasília, no final da década de 50 do século passado, 
que abriu caminho para sensíveis mudanças econômicas, ampliando, assim, a frente de expansão agrícola direcionada para o mercado exportador, o agronegócio, monocultor e excludente.

Ressaltamos que o acesso à terra e aos recursos naturais do Cerrado começaram a ser limitados por essa nova territorialização que, de forma intensiva, deu início à produção comercial de soja, arroz, cana e eucalipto, inicialmente no município de Balsas, expandindo-se, depois, para outros municípios dessa região, como é o caso de Carolina e Riachão.

N essa área onde tradicionalmente passavam rebanhos criados a solta, campos de soja e arroz vão, pouco a pouco, tomando o lugar da antiga paisagem, com ameaça de poluição da água, do solo e do ar, devido ao uso indiscriminado de agrotóxicos, e de devastação de extensa área de cerrado sul-maranhense. Velhos costumes e tradições vão se desintegrando, ao mesmo tempo em que as categorias dos vaqueiros, agregados, posseiros, vão se transformando em assalariados da agricultura mecanizada. 0 secular mundo pastoril sobre o qual tão pouco se tem investigado vai lentamente se desmoronando. (CABRAL, 2008, p. 25)
Com a chegada do agronegócio, que impõe novas formas de relações com 0 território, antes livre para o uso coletivo por parte dessas populações, que, de uma forma muito rápida, transforma a paisagem natural do Cerrado em áreas de extensas monoculturas, dois tempos coexistem em um mesmo espaço, impondo novos padrões de uso da terra e de consumo. Neste sentido, a territorialidade dessas populações é influenciada por essa nova dinâmica territorial modernizante que tem alterado muito rapidamente esse modo de vida tradicional sertanejo. A chegada das monoculturas da soja, do eucalipto e da cana para a região da Chapada das M esas, embutida no território do agronegócio, que tem ligações em rede com outros tantos territórios dessas mesmas características e que ocupa as áreas agricultáveis e as transformam, seguindo um modelo de produção, pode ser vista tanto na escala local, como mundial. Ou seja, evidencia-se um pacote de mudanças que incluem a questão ambiental, com o desmatamento acelerado da vegetação nativa, a alteração da paisagem, o uso intensivo dos recursos hídricos para a irrigação, a introdução de agrotóxicos contaminantes para o solo, água, ar e para toda a cadeia alimentar, além das novas formas de relações trabalhistas e de uso da terra, impostos pelo modelo agroexportador.

$\mathrm{Na}$ década de 1980, nesse 
território, que é palco de uma nova ocupação pelo agronegócio, as diversas territorialidades produzidas pelos seus habitantes coexistiram. Por último, como uma forma de conservação do bioma do cerrado, temos a criação de uma U nidade de Conservação, que possui como determinante a imposição de novas formas de convivência com 0 ambiente, anteriormente "livre" para 0 uso comunitário dos povos do Cerrado.

O PNCM está inserido nos territórios dos municípios de Carolina, Riachão e Estreito, ao sul do estado do $M$ aranhão, a atual fronteira do agronegócio e que sofre uma grande pressão para o uso agrícola dessas terras, em sua maioria de grande fertilidade. A existência do PNCM no espaço territorial da região da Chapada das M esas promove uma singularidade representada pela paisagem natural em relação a outras regiões do Brasil. Possui os seus desenhos em formatos tabulares que representam uma herança geológica para toda a população que habita essa região.

Essa U nidade de Conservação da categoria de proteção integral foi instituída como uma forma de conter o avanço rápido do agronegócio e de tentar proteger uma parcela do bioma cerrado dessa área. Essa categoria, bastante restritiva, encontra-se inserida no Sistema Nacional de U nidades de Conservação que tem como "objetivo básico das U nidades de Proteção Integral é preservar a natureza, sendo admitido apenas 0 uso indireto dos seus recursos naturais, com exceção dos casos previstos nesta Lei" (MMA/SBF - SNUC, 2004, p.15).

Para Diegues (2000), essa forma antiga de convivência das populações tradicionais com 0 ambiente permite que se discuta a forma como é pensada a criação de unidades de conservação para a preservação de biomas, como é o caso do PNCM, em que o deslocamento dos sertanejos está previsto, sem que seja considerada a sua história, sua presença e a paisagem cultural local, reflexo dessa intensa relação do ser humano com o meio. Esse modelo de área protegida de uso indireto, que não permite haver residentes no interior da área mesmo quando se trata de comunidades tradicionais presentes há muitas gerações, parte do princípio de que toda relação entre sociedade e natureza é degradadora e destruidora do mundo natural e selvagem - a wilderness norte americana - não havendo distinções entre as várias formas de sociedade (a urbano industrial, a tradicional, a indígena, etc.). (M M A/ SBF -SN U C, 2004, p.7)

Ressaltamos, assim, que 0 
conhecimento e a valorização dessas populações tradicionais produz informações que poderão ser utilizadas para a consolidação da implementação dessa unidade, em que as populações tradicionais possuem 0 direito de permanecer no seu interior mediante a formalização de um Termo de Compromisso. (MMA/SBF - SNUC, 2004)

O sertão e os sertanejos

Gomes \& Fernandes (2014, p. 21) apontam que $0 \mathrm{M}$ aranhão não foi, desde sempre, considerado inserido no sertão. Esse imaginário apenas se constitui "quando o poder político concentrou-se no centro-sul da América Portuguesa; também passou a ser sertão pela oposição à ideia de civilização que emanava da Corte do R io de Janeiro".

A constituição de ideia de sertão também nos encoraja a encontrar 0 sertanejo que constitui e conforma essa ideia. Assim, é possível afirmar que o sertanejo é um povo que vive há mais de um século nessa região, em sua maioria, como agregado das grandes propriedades instaladas com a expansão da pecuária e, notadamente, vive reinventando a sua própria existência. Essa população tem desenvol vido práticas de convivência com 0 bioma Cerrado, resistindo e reformulando formas de subsistência que a mantêm tradicionalmente singular perante os novos costumes impostos pela transformação rápida desse território. Nesse sentido, os sertanejos apresentam-se como um contraponto aos padrões homogeneizantes da sociedade de consumo que impõe novas formas de uso e costumes ao território, sem uma reflexão sobre o que nele existe e que necessita ser conservado. Nesse processo, reivindicam a manutenção de seu espaço e seu modo de vida, alertando-nos para a compreensão de um "fenômeno não somente espacial e histórico, mas de confrontação cultural e ideológica" (SILVA, 2007, p. 285).

Reconhecemos uma atuação desse grupo em uma perspectiva do paradigma territorial contra-hegemônico, amparandonos no conceito desenvolvido por Haesbaert (2014), que seria justamente a resistência que esse grupo apresenta à lógica hegemônica, apoiada na agricultura capitalista, com forte viés produtivista, homogeneizante e mercantil.

Assim, falar dos sertanejos é falar de grupos que possuem um movimento secular de expansão da ocupação humana dos desertos interiores. $\mathrm{Na}$ vastidão do mediterrâneo interior configuram-se diversas variantes de modos de vida que são adaptações locais e funcionais dessa expansão sertaneja. (DIEGUES, 2000, p. 51) 
Esses sertanejos desenvolvem atividades de subsistência com sua família, comercializam o excedente da produção, assumem atividades coletivas, quando é a época da produção da farinha de mandioca e, também, na coleta de frutos do Cerrado e festejos religiosos. Apesar de serem camponeses, adota-se aqui 0 termo Sertanejo do Cerrado para diferenciá-los de outros grupos da mesma categoria de camponeses. Little $(2002$, p. 9) ressalta a importância dessas populações como tradicionais:

As populações extrativistas representam outros grupos sociais incluídos na categoria de tradicionais e tendem a ser reconhecidos pelos produtos que extraem e vendem no mercado seringueiros, castanheiros, babaçueiros, pescadores - , apesar deste ser apenas um elemento de um complexo sistema de adaptação que inclui caça, pesca, agricultura, fruticultura e criação de pequenos animais (Moran 1974). No plano fundiário, o que marca os grupos extrativistas da Amazônia é a apropriação familiar e social dos recursos naturais, onde as "colocações" são exploradas por famílias, os recursos de caça e pesca são tratados na esfera coletiva e a coleta dos recursos destinados ao mercado é feita segundo normas de usufruto coletivamente estabelecidas.

É importante considerar o papel singular dessas populações tradicionais na conservação da biodiversidade, já que, com seu modo de vida e sua intensa rel ação com - Cerrado, têm assegurado a própria manutenção do bioma. Cabe ressaltar 0 tipo de atividade desenvolvida: extrativismo vegetal, caça, pesca, agricultura em sistema de pousio, aproveitamento das fibras, do couro, das frutas do cerrado, entre outros. 0 ol har e 0 aproveitamento do sítio, do ponto de vista físico, também merece menção, como a agricultura desenvolvida nas encostas e fundos de vale e a solta de gado e extrativismo na chapada (observação de campo que coincidem com PortoG onçalves (2008, p. ,43)

Os Povos do Cerrado são portadores de um enorme acervo de conhecimentos fundamentais para quaisquer políticas que se queira fundada numa sustentabilidade ambiental e não simplesmente numa sustentabilidade ecológica. A final, a sustentabilidade ambiental pressupõe não só a dimensão ecológica, mas todo o horizonte de valores onde a participação protagônica e democrática dos 
povos dos cerrados, com a autoridade que seus conhecimentos Ihes emprestam, sejam o suporte para a justiça social, para a vida e para a paz (PORTOG ON ÇA LVES, 2008, p. 43).

Essas populações desenvolveram seus sistemas de vida longe dos núcleos dinâmicos da economia nacional. De acordo com Diegues (2000, p. 31), "adotaram o modelo da cultura rústica, refugiando-se nos espaços menos povoados, onde a terra e os recursos naturais ainda eram abundantes, possibilitando sua sobrevivência e a reprodução desse modelo sociocultural de ocupação do espaço e exploração dos recursos naturais".

Esse modo de vida, com essa arquitetura vernacular, com 0 uso dos recursos locais nas atividades da vida cotidiana, esse profundo conhecimento dos frutos e plantas do cerrado, dos solos e locais para desenvolvimento da agricultura de subsistência, com experiências coletivas envolvendo a produção da farinha, a vida comunitária, marcada pelas rezas e festas, poderia nos dar pistas de outro paradigma societário. Nesse sentido, corroboramos as reflexões de Porto Gonçalves, que afirma que:

Essas populações desenvolveram ao longo dos séculos, modos de vida com uma relação orgânica com os ecossistemas, baseados na sua produção biológica primária (extrativismo, caça, pesca) e em estratégias agropecuárias que otimizavam as potencialidades do ambiente de transformar energia solar em alimentos, carnes e fibras, utilizando de forma heterogênea e diversificada.

(PORTO-

G ONÇALVES, 2008, p. 122)

Desenvolveram, dessa forma, um "patrimônio comunitário" formado por um conjunto de valores e crenças, conhecimentos e práticas, técnicas e habilidades, instrumentos e artefatos, lugares e representações, terras e territórios, assim como todos os tipos de manifestações tangíveis e intangíveis existentes em um povo. Através disso, expressam seu modo de vida e organização social, sua identidade cultural e suas relações com a natureza (M ALDONADO, 2009).

Entendemos que 0 conceito discutido por Little (2001) de "cosmografia", que se refere à relação que um determinado grupo social constrói com seu território, aplica-se à realidade estudada já que consiste em

saberes ambientais, ideologias e identidades - coletivamente criados e historicamente situados 
- que um grupo social utiliza para estabelecer e manter seu território. A cosmografia de um grupo inclui seu regime de propriedade, os vínculos afetivos que mantém com seu território específico, a história da sua ocupação guardada na memória coletiva, o uso social que dá ao território e as formas de defesa dele. (LIT T LE, 2002, p.4)

Nessa perspectiva, a defesa desse território passa pelo sentido de pertencimento que se traduz na relação que essa população tem com esse ambiente.

Buscamos apresentar, aqui, algumas narrativas que serão expostas para trazer um pouco desse cotidiano e a forma de viver dessa população de sertanejos em ligação direta com uma natureza que os fez ser como são e vice versa. T raduz a forma de ser do Cerrado, que, em determinados momentos, como na época das águas, é muito lamoso, barrento e, em outros, é muito seco, quase árido em determinados lugares, mas que possui, sempre, muitos frutos e sementes para serem disseminados e colhidos para dar nova vida a outro ciclo que se inicia. Os diversos tempos se sobrepõem e compõem esse território com sua maravilhosa sociobiodiver sidade.

Dessa forma, foram realizadas entrevistas que um roteiro predefinido, contemplando 14 habitantes da área de abrangência do PNCM, nos povoados Canto Grande, Solta e São José dos Pereiras, no município de Carolina e três habitantes do interior do PNCM. Destacaremos as entrevistas utilizadas neste trabalho.

São muitos os relatos sobre 0 impacto das mudanças, tanto positivos quanto negativos. Em relação à construção das moradias tradicionais, há a queixa recorrente de que os recursos naturais, como a piaçava e o babaçu, estão mais escassos, exigindo alto custo de transportes. Além disso, os jovens já não dominam a técnica tão bem, em especial no que diz respeito à época de retirada da palha e ao seu tratamento para que não apodreça ou atraia lagartos.

Sr. Clodomir, morador do povoado Solta, que se localiza na área de abrangência do Parque Nacional da Chapada das Mesas, relatou-nos que a piaçava é considerada como uma praga do pasto. Como, no povoado, há muitas criações de gado solto nas áreas de pastagens, essa piaçava tem ficado escassa, pois é cortada. Além disso, utilizam-se das queimadas como limpeza de pasto e da vegetação, 0 que tem provocado a diminuição dessa fibra. Ele associa essa questão com as dificuldades existentes atualmente para cobrir as casas com a palha de piaçava devido à diminuição do produto, à distância, ao fato de que não 
compensa mais fazer a cobertura com esse tipo de material, levando, então, ao uso da telha de barro. Segundo o entrevistado, 0 povo do sertão mais antigo conhece a forma de trabalhar com esse material, ao passo que os mais novos, que não os utilizam para cobrir suas casas, nem se interessarão em aprender. . Dona Deusina, moradora do interior do Parque na localidade de Riacho Fundo, na Gleba Serra Alta, casada com Sr. Moisés, que além de agricultor é também um poeta autodidata, mãe de 13 filhos, também relatou sobre alterações ambientais. Falou sobre o modo de vida específico do sertão, dos modos de fazer casas, preparar alimentos, de escolher 0 terreno onde plantar cada tipo de alimento e também sobre a produção de farinha.

Importante mudança relatada refere-se à produção de farinha (Figura 2) para o próprio consumo, devido à dificuldade em continuar a produzir farinha, tendo em vista seu envel hecimento e de seu marido e a falta de braços para o mutirão que viabiliza a produção.

Destacamos 0 povoado Canto G rande, que fica na área de abrangência do PNCM, considerado uma localidade produtora de farinha de mandioca. Segundo alguns relatos de moradores, a forma de fazer essa farinha tem características regionais, conhecida como farinha de "puba" ou farinha dágua, pelo

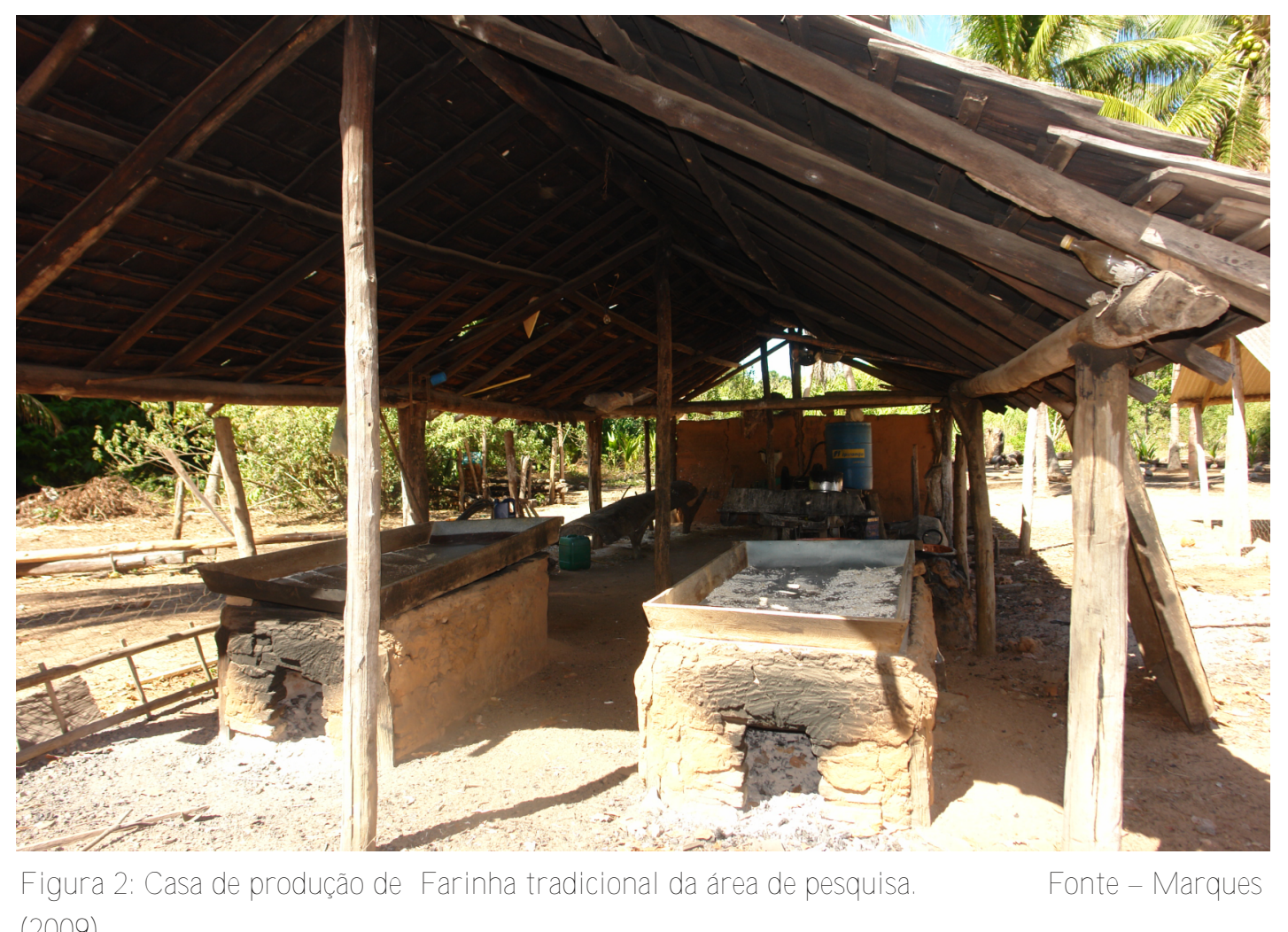
(2009). 
fato de ficar de molho na água para sua fabricação. $M$ arcelo nos informou que,

Para fazer a farinha. tem que acordar às $3 \mathrm{~h}$ da manhã, passa 0 dia e noite até $6 \mathrm{~h}$ da manhã do outro dia (no caso, para torrar a farinha, dura 26 horas). Muitas pessoas do povoado pararam de fazer a farinha devido à poeira (líquido que sai da mandioca que é prejudicial à saúde que mata até os animais) e, para 0 homem, a fumaça que sai na torra da farinha. (D epoimento de Marcelo do povoado Canto Grande, maio de 2012.)

Quando indagado se queria que seus filhos vivessem no sertão, respondeu: "Não quero essa vida para meu filho, mas quero que ele tenha esse pedacinho do sertão".

Este relato demonstra um pouco das dificuldades encontradas por essa população estudada, para poder sobreviver e continuar a desempenhar suas atividades de roça, fabricação de alimentos, extração de produtos do Cerrado, artesanato, entre outras. Hoje as atividades são um pouco diferentes, mas permanecem as atividades na roça, como o plantio de feijão corujinha e manteiguinha e da mandioca, bem como a coleta de frutos como o bacuri, - açaí, que é conhecido regionalmente como juçara e da bacaba. Permanece, ainda, a prática comunitária da produção da farinha, considerada a melhor da região, segundo vários depoimentos de moradores do local.

Sr. Cirilo (Figura 3), morador do interior do Parque, é um mestre artesão autodidata, sendo ele mesmo que construiu a sua casa de taipa (Figura 4), com cobertura de palha de piaçava e a maioria dos utensílios que utiliza no seu dia a dia, como o pilão, os tambores, as cuias, cabaças para colocar água, cestaria, entre outros. Trabalha muito bem com o curtimento do couro, produzindo, assim, assim a sua existência com o Cer rado.

Em sua gleba de terras, de pouco mais de 30 hectares, ainda sem registro cartorial, ele planta produtos para sua sobrevivência, vivendo com sua filha e um neto. Reproduzimos uma parte de sua entrevista em que nos relatou como é que faz a sua roça:

D e primeiro capinava, hoje não capina mais, mas aí, depois de queimada, podia plantar. Quando chove, planta arroz, planta milho, planta mandioca, planta feijão, banana, mamão, gergelim, tem 0 algodão que fazia rede Tudo a gente plantava. E u já mexi com tudo no mundo, a coisa que eu nunca mexi foi roubar e matar, até que matar, tem hora que me dá vontade de matar, mas aí é uma coisa muito complicada. (D epoimento de $\mathrm{Sr}$ 
Cirilo coletado em maio de 2012).

Sr. Cirilo relatou-nos ainda que participa frequentemente das festas religiosas do povoado mais próximo, denominado Buritirana, e também das

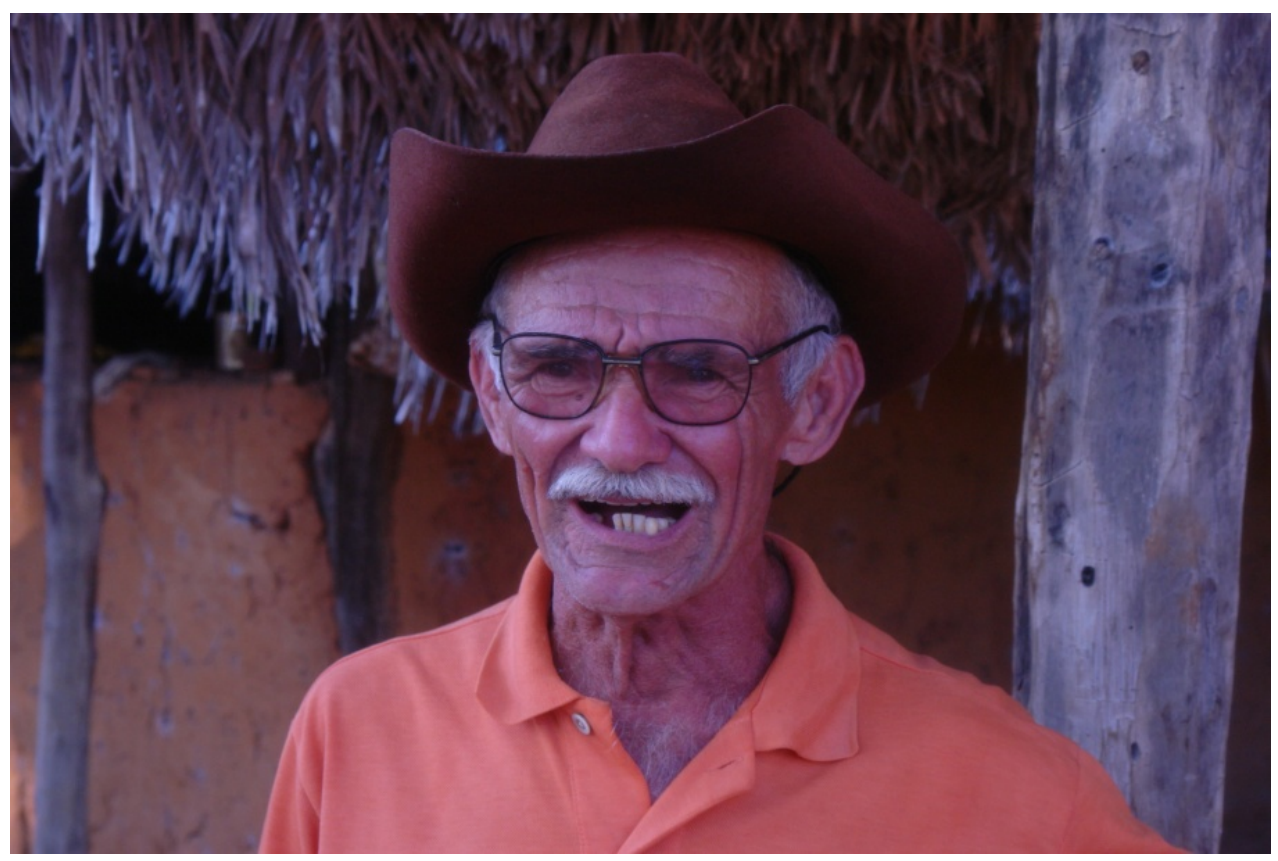

Figura 3 - Sr Cirilo, morador tradicional do PN CM . Fonte - M arques (2012).

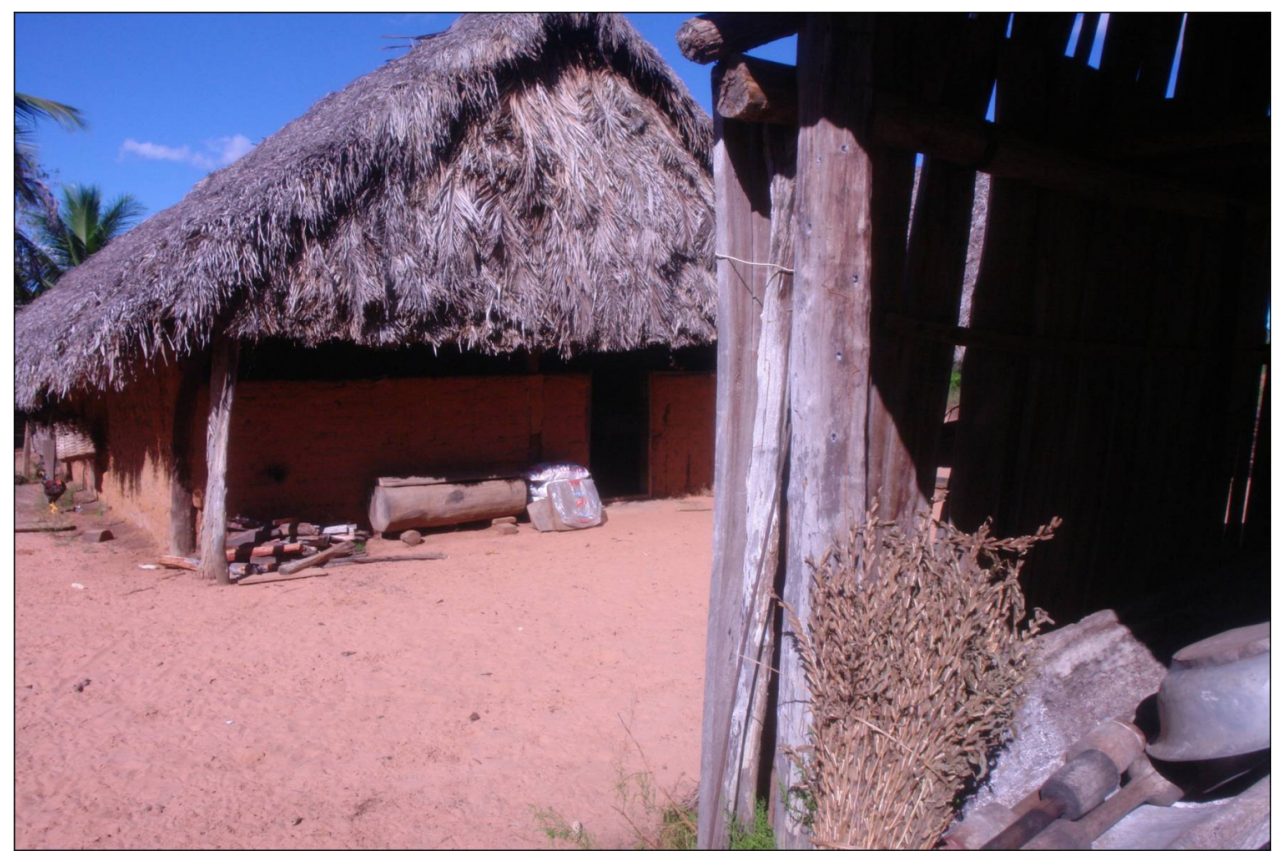

Figura 4 - M oradia tradicional Sr Cirilo, feita por ele com pal ha de piaçava e taipa de terra do lugar. Fonte - M arques (2012).

ESPAÇ O E C U LTU RA, UERJ, RJ, N . 40, P. 157-180, JU L./DEZ. DE 2016

http://www.e-publicacoes.uerj.br/index.php/espacoecultura/

\section{9}


rezas. Seus saberes sobre a localidade estão intrinsecamente ligados ao Cerrrado, de onde provêm diversas substâncias que usa para tratar o couro, resinas de espécies que ajudam nesse tipo de artesanato que desempenha muito bem. U ma herança que trouxe da lida com o gado. Vive com pouca renda, como a maioria do sertanejo desse território, utiliza do sistema de trocas e possui estreita relação com a vizinhança.

A perspectiva religiosa manifestase nas festas comunitárias, como no povoado de Solta, que mantém a tradição da festa do divino, como descrito na fala de dona $\mathrm{M}$ aria H elena:

Quando é no dia do divino, inclusive no dia do divino que é domingo agora, tem duas reza, que nois chama reza, né, do divino. U ma na casinha ali na beira da estrada e outra depois do lago na casa de uma cumadi minha que ela festeja todo o ano. Aí ela faz reza, aquele terço, o pessoal ajuda, todo mundo ajuda a ir rezar aquele terço, aí, depois, tem um grande almoço pra todo mundo que participar, aquele almoço é dado, não é vendido. (D epoimento de D ona M aria Helena, coletado em maio de 2012)

A festa do divino, segundo depoimento dos nossos entrevistados dos povoados Solta e São José dos Pereiras (Figura 5), ocorre no período depois da
Páscoa (abril), enquanto a comemoração de Corpo de Cristo (junho), é feita em coletividade com a comunidade, tendo vários festeiros que pagam promessas por graças al cançadas. D ona E Ivira (F igura 6), moradora do povoado Solta, ao perguntarmos sobre a importância para ela da festa do divino, disse-nos:

Porque o divino é um santo milagroso, a gente tem muita fé nele. Aí a gente faz essas promessas assim, né, tem que cumprir. [ ...] começa, assim, por exemplo, aqui nesse povoado[ ...] ele sai lá da casa dele, por exemplo, ele sai daqui, aí corta ali até chegar 11 horas. Quando chegar 11 horas, eles param pro almoço, quando são duas horas, torno a ir cantar nas outras casas, aí dorme Acontece que tem muita gente que faz promessa assim, pra ser três dias, né Outro não, é só um dia, aí quando é no dia do divino, aí ele reza aquele terço, às vezes dão muitas coisas, muita comida, muita coisa assim, nél. (D epoimento de Dona E Ivira, coletado em maio de 2012)

A creditamos que as relações entre 0 território e a paisagem formam a configuração de identidades e que as práticas sociais surgem a partir de uma determinada relação com 0 espaço, conformadas a partir de um universo simbólico, ancorado nos campos de sentido 


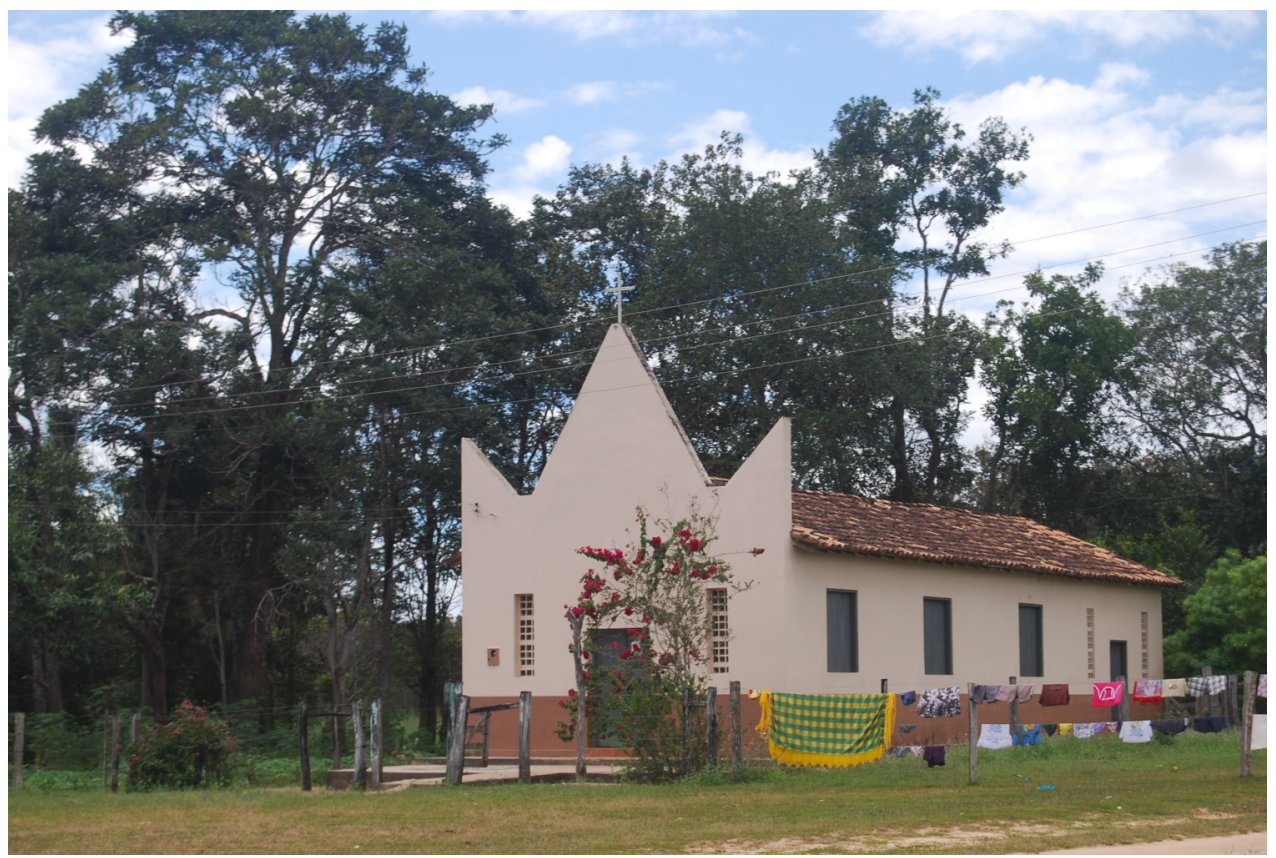

Figura 5 - I greja católica no povoado de Solta. Fonte - M arques (2012).

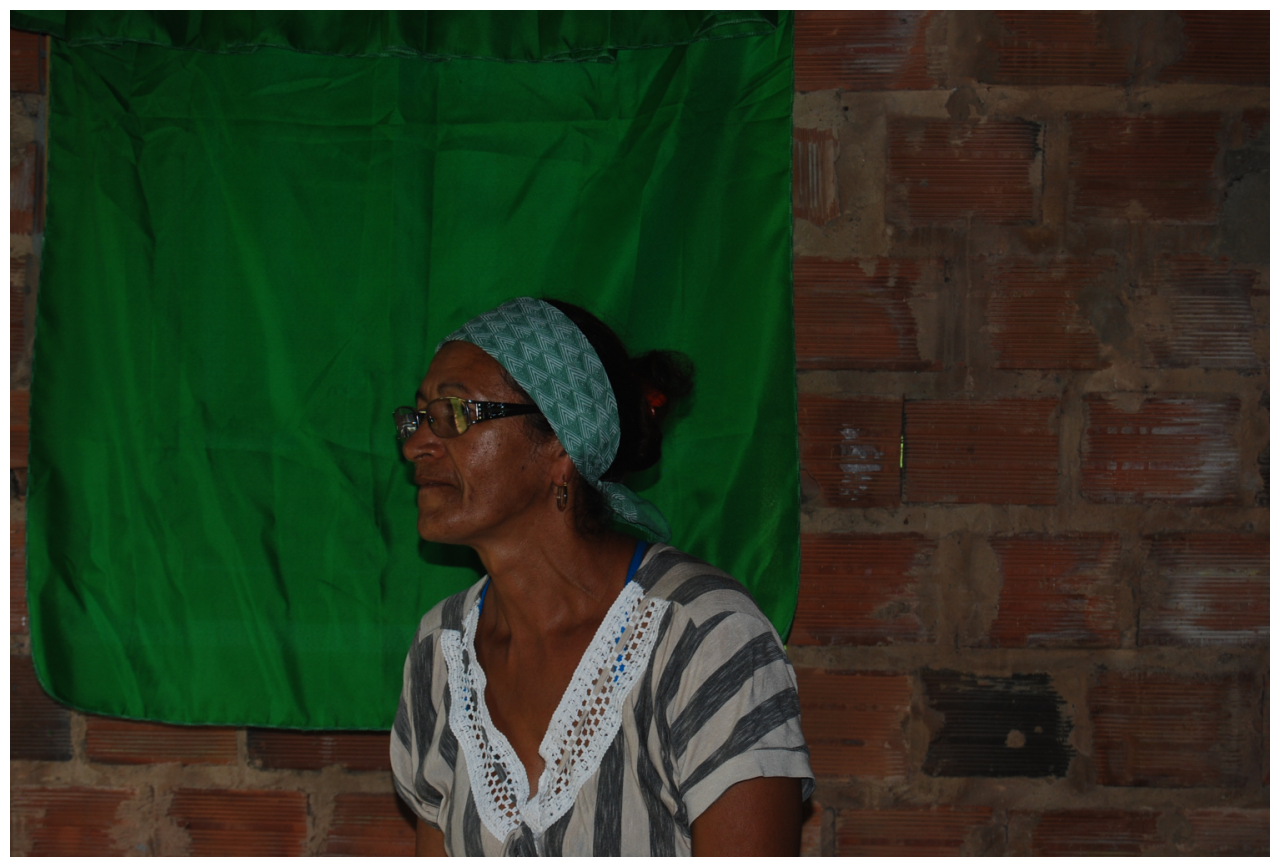

Figura 6 - D ona E Ivira, moradora do povoado Solta. Fonte - M arques (2012).

e significado que os homens constroem na e pela relação com seu espaço, com o lugar e com o universo material que o circunda.
A territorialidade do sertanejo do Cerrado é perceptível na paisagem por meio de sua cultura. Ele possui uma convivência com 0

ESPAÇ O E C ULTURA, UERJ, RJ, N . 40, P. 157-180, JU L./DEZ. DE 2016

http://www.e-publicacoes.uerj.br/index.php/espacoecultura/ 
ambiente muito intensa, apropriando-se dele e transformando o espaço em que vive, com pouca alteração na paisagem. U tilizase dos recursos naturais para sua serventia, como é o caso do Buriti, como relatado por Rigonato e Almeida (2003, p. 12):

D o fruto faz-se o óleo, e o doce feito da polpa é uma das delícias do paladar do sertanejo. As folhas são utilizadas pelas populações tradicionais no recobrimento das residências, do paiol, do chiqueiro e dos galinheiros, além da fabricação de peneiras, quibana, couraça e outros artesanatos.

A cultura do sertanejo do Cerrado ou povo do Cerrado, por meio de uma dimensão sociológica, é percebida como o resultado de todas as ações humanas, sendo que uma depende da outra para existir. $\mathrm{N}$ esse sentido, o ser humano transforma 0 ambiente, mas também é transformado por ele, em um pleno movimento que acontece no decorrer do tempo, explicitado por $M$ achado (2007, p. 139):

A cultura não envolve simplesmente o ser humano, mas penetra nele, modelando a sua identidade, personalidade, maneira de ver, perceber, pensar e sentir 0 mundo. É o conjunto de entidades subjetivas e objetivas com extrema diversidade e multiplicidade, ou seja, pluraridade. [...] Dessa maneira, a forma de ser das pessoas de uma determinada cultura apresenta características comuns, que as tornam semelhantes entre si e diferentes de pessoas de outras culturas.

Nessa perspectiva, os costumes do povo que habita a Chapada das M esas e convive diretamente no bioma Cerrado é muito semelhante aos dos seres humanos de outras áreas, que utilizam a mesma cobertura vegetal, com características físicas, biológicas e culturais, que os diferenciam de outros povos de outros biomas. Entretanto, essa cultura se traduz como o modo de vida do povo sertanejo do Cerrado, que possui uma identidade própria que, ao mesmo tempo, caracterizao e 0 diferencia de outros povos tradicionais.

Sobre essa questão conceitual acerca do território e suas diversas abordagens, Rogério Haesbaert, em seu texto "Des-caminhos e perspectivas do território" (2004, p. 93), discorre sobre a necessidade de se superar a "dicotomia material/ideal," propondo um território que envolva, simultaneamente, "a dimensão espacial concreta das relações sociais e 0 conjunto de representações sobre 0 espaço ou o "imaginário geográfico" que não apenas move como integra ou é parte 
indissociável destas relações".

Outra forma de análise de território pode ser concebida por meio da geografia cultural. $N$ as sociedades tradicionais, onde existe uma ligação mais intensa com os espaços de vida, com a dimensão imanada da apropriação simbólico-religiosa, 0 sagrado está presente por meio dos mortos (Haesbaert, 2004, p.111). Segundo essa concepção, nós pertencemos a um território, não o possuímos, moramos nele. Perder um território pode significar 0 desaparecimento de determinadas culturas que o habitavam.

Diante disso, pressupõe-se que as populações sertanejas possuem uma herança construída no decorrer do tempo, devido às suas necessidades de sobrevivência e adaptação ao meio. Como arcabouço para essa afirmação, destaca-se uma característica fundamental observada no decorrer das incursões em campo: a autonomia que os sertanejos têm exposto em seu modo de vida. N esse sentido, neste trabalho, defende-se a vinculação dessa com o princípio da autodeterminação que encontra respaldo na reflexão de Diegues (2000) que vincula esse modo de vida a um sentido de pertencimento a uma cultura distinta. $N$ esse sentido, defende-se 0 direito dessas populações determinarem suas prioridades e exercerem seu protagonismo frente aos órgãos governamentais em decisões que impactem seu futuro, tese defendida por Carneiro da Cunha e Almeida (2000).

Porto-G onçalves destaca que um primeiro esforço para esclarecer sobre a importância dessas populações e sua cultura vem sendo 0 de demonstrar a sustentabilidade econômica do agroextrativismo no Cerrado,conforme a rica tradição indígena, quilombola, camponesa vem fazendo ancestralmente. Assim, vêm demonstrando que 0 Cerrado não somente valor econômico, mas também que os agroextrativistas são capazes de organizar empreendimentos solidários a partir desse potencial (PORT 0G ON ÇALVES, 2008, p.82).

Essas formas de uso tradicional do Cerrado produzem uma resistência que foi notada em grande parte das falas dos nossos sujeitos da pesquisa, que, em vários momentos, valorizaram o seu lugar, as suas tradições e também a forma como vivem nesse território, de uma maneira simples e sem grandes dependências do mundo exterior. Uma conquista fruto de um século de desenvolvimento de modos de fazer, criações de instrumentos de usos para o cuidado com a terra e práticas agrícolas de subsistência, construções de suas moradias artesanalmente, além de um 
vasto conhecimento no uso de plantas medicinais e frutos do cerrado, utilizando seus recursos de uma maneira sustentável.

Território, territorialidade e conflitos socioambientais

Percebe-se, no discurso hegemônico, que a construção simbólica do sertão, como vazio ou lugar do atraso, da aridez, da aspereza, da incultura, da ignorância, é um pressuposto para desvalorização da territorialidade dessas populações para, na esteira desse discurso, reafirmar a modernidade, o progresso, a produtividade, a riqueza, vinculadas à importância econômica do agronegócio. Assim, consideramos as contribuições de $H$ aesbaert (2014, p.12):

N uma sociedade em que tanto se fala em hibridismo e trocas culturais, a definição clara de territórios por uma base étnica pode parecer paradoxal. $M$ as 0 mais importante é perceber que esses territórios dos povos tradicionais são também uma conquista desses grupos e que, ainda que indiquem certa separação étnico-cultural - mas que pode representar a única condição que resta para sua sobrevivência enquanto culturas distintas da terra e a instituição do seu usufruto coletivo. Pelo lado socioeconômico, trata-se de espaços relativamente vastos (principalmente na região Amazônica) que estão vedados à apropriação privada e que, pelo menos em tese, são de usufruto comunitário, exclusivo desses grupos sociais -, implicam em outra conquista que é a subversão da lógica privatista.

A territorialidade, segundo Sack (2004, p.105), vai além da dimensão política (controle de grupos em determinados contextos geográficos de lugar, espaço e tempo), possui também uma ligação com as dimensões econômica ("uso da terra") e cultural ("significação" do espaço), esclarecendo que a territorialidade está ligada "[ ...] ao modo como as pessoas utilizam a terra, como elas próprias se organizam no espaço e como elas dão significado ao lugar."

Dessa forma, a análise dessa territorialidade, incluindo o sistema de representações, símbolos e mitos que essas populações constroem, demonstram como elas agem sobre o meio. É também com essas representações e com o conhecimento empírico acumulado que desenvolvem seus sistemas tradicionais de manejo, tornandoos patrimônio cultural, sendo necessária a sua conservação, uma vez que 
o patrimônio cultural de um povo é formado pelo conjunto de saberes, fazeres, expressões, práticas e seus produtos, que remetem à historia, à memória e à identidade desse povo.

A preservação do patrimônio cultural significa, principalmente, cuidar de bens representativos da histórias e da cultura de um lugar [...] de cuidar também dos usos, costumes e manifestações culturais que fazem parte da vida das pessoas que se transformam ao longo tempo. (IPHAN, 2007, p. 12).

Imersos nesta complexidade demonstrada até aqui neste trabalho, destacamos que existe a urgência na valorização e no conhecimento desse grupo humano estudado, para que possamos ter a conservação desse patrimônio cultural que é muito singular para a composição da cultura tradicional brasileira.

A questão aqui, neste momento, após a compreensão desse território e territorialidade dessa população tradicional, traz uma discussão sobre os principais impactos socioambientais que está em curso na área de estudo, o Cerrado da região de abrangência do | PNCM, que apresenta uma enorme sociobiodiversidade, como ressaltado por Porto-Gonçalves (2008, p.149), quando comenta sobre o agronegócio, destacando a importância sociocultural:

0 grande conflito que se dá hoje nos Cerrados - de um lado, aqueles que arrogantemente ignoram toda essa enorme riqueza de vida, tanto no sentido biológico como cultural, e querem impor a cultura do U M e para poucos e, não bastasse a desigualdade e concentração de riquezas e poder que engendram, impedem que essas outras e diferentes matrizes de racionalidade que ali historicamente se desenvolveram possam se reproduzir.

Essas terras de uso comum, das comunidades sertanejas, foram paulatinamente encampadas por esse novo modelo de agricultura, que os tem deixado à mercê desse processo produtivo. Como já descrito anteriormente, não bastasse essa perda do território para o uso comum, perde-se também os recursos como a água, que tem diminuído cada vez mais, segundo relatos dos nossos entrevistados.

0 autor destaca que os Cerrados vêm sendo alvos constantes de desmatamentos. 0 complexo reflorestador siderúrgico-celulósico, provocado pela monocultura do eucalipto, é, rigorosamente, do ponto de vista científico, agente de um modelo produtivo que impacta Cerrados, água e gente, que, de 
sustentável, não tem nada (PORTOGONÇALVES,2004).

Além desses impactos diretos causados pela alteração da paisagem pelo agronegócio, existem também as alterações no bioma Cerrado do PNCM que têm sido constituídas no decorrer do tempo, pela ocupação do gado extensivo e no sistema de plantio denominado roça no toco, que é um sistema tradicional de plantio que utiliza o fogo para limpeza da área a ser cultivada, um sistema que mantém alguns remanescentes de árvores (tocos) e necessita da abertura de novas áreas florestadas para a sua implantação. (IBAM A, 2006)

Associadas a esses problemas, as queimadas para a limpeza de pasto têm provocado grandes impactos, na época seca, com grandes áreas atingidas, pois elas se transformam em grandes incêndios, provocando a destruição de moradias tradicionais e de cultivos para a subsistência.

E mbora exista um grande potencial de fauna no PNCM, este convive com inúmeros problemas relacionados à perda de habitat, seja pelo desmatamento e queimadas, que são constantes, pela caça predatória, que tem causado o desequilíbrio entre as espécies, promovendo 0 aumento sem controle de algumas em detrimento da diminuição de outras.

0 processo contínuo do uso do fogo para a limpeza de pastos, característico da criação de gado extensivo, força a paisagem a se modificar, sofrendo impactos constantes, perceptíveis no momento atual com as áreas de pisoteio, com processos erosivos, resultantes desse mau uso e de incêndios periódicos.

Todo esse processo de impactos socioambientais nos alertam para a necessidade de um aumento de políticas públicas inclusivas para essa população apresentada neste trabalho, pois, no momento presente, há muitas demandas a serem sanadas no que diz respeito à qualidade de vida e à sustentabilidade ambiental dessa região.

\section{Considerações Finais}

As reflexões apresentadas neste trabalho nos alertam, em um primeiro momento, para a grande transformação que está ocorrendo com o bioma Cerrado, em específico este da região sul do estado do $M$ aranhão. Essa questão põe em risco uma magnífica sociobiodiversidade que existe há mais de 11 mil anos, segundo estudos sobre a origem dos primeiros habitantes desse território.

Esse risco socioambiental é reforçado, quando trazemos ao conhecimento da sociedade a singularidade dessa população tradicional sertaneja, que possui um "patrimônio comunitário" 
formado por um conjunto de valores e crenças, conhecimentos e práticas, técnicas e habilidades, instrumentos e artefatos, lugares e representações, terras e territórios, assim como todos os tipos de manifestações tangíveis e intangíveis que foram percebidos no decorrer desta pesquisa.

Há a necessidade de uma atenção direcionada para essa região no sentido de valorização dessa população que se respalda na reflexão de Arruda (1999) sobre a análise dos mecanismos socioculturais desses grupos tradicionais que pode indicar outras formas de ocupação do território, de manejo do meio ambiente, perspectivas econômicas alternativas ao modelo hegemônico e possibilidades de se construir com as comunidades já articuladas ao mercado global, caminhos para exploração sustentável dos recursos.

Também é necessária a ampliação do diálogo entre as instituições que atuam nesse território, a fim de assegurar a permanência desse grupo em seu território e a manutenção do Cerrado em pé, condição sine qua non para o equilíbrio e a manutenção dessa paisagem natural e cultural.

Notas

* Professora Adjunta III da U niversidade Estadual do $M$ aranhão, analista ambiental do Instituto Brasileiro de Meio Ambiente e dos Recursos $\mathrm{N}$ aturais Renovaveis-M A , atuando principalmente nos seguintes temas: educação ambiental, desenvolvimento sustentável, planejamento ambiental, ordenamento territorial, unidades de conservação, terrritorialidade e impactos ambientais.

** Professora A djunta da U niversidade de Brasília. Desde 2001 é fellow do Programa Lead Internacional, organização ligada ao desenvolvimento de lideranças na temática da sustentabilidade. Trabalha e pesquisa os temas: Geografia e Infância; Educação em contextos culturais específicos; Questões teóricometodológicas referentes ao Ensino de Geografia nos anos iniciais da escolarização.

${ }^{1}$ No bojo do processo de ocupação das terras $D$. João, regente de Portugal publica Carta Régia em 1798 autorizando o Governador a explorar terras até 0 rio Tocantins. (GOMES; FERNANDES, 2014, p. 25)

\section{Referências bibliográficas}

ANDRADE, M. P., SOUZA FILHO, B. (Org.). Os gaúchos descobrem o Brasil: projetos agropecuários contra a agricultura camponesa. São Luís: E dufma, 2008.

ARRUDA, R. "Populações Tradicionais" e a Proteção dos Recursos $N$ aturais em U nidades de Conservação Naturais em Unidades de Conservação. A mbiente \& Sociedade, no. 5, p. 79-92, 1999.

CABRAL, M. do S. C. Caminhos do Gado: conquista e ocupação do sul do $M$ aranhão. São Luís: Sioge, 1992. 
- Caminhos do Gado: conquista e ocupação

do sul do M aranhão. - 2 ed. - São Luís: Edufma, 2008. São L uís, M A : E dições SE CM A, [ 1992]

CAMPOS. N. J. de. Populações Tradicionais e formas de uso comum. In: ALVES, V. E. L. (Org.). Modernização e regionalização nos cerrados do Centro Norte do Brasil: Oeste da Bahia, Sul do $M$ aranhão e do Piauí e Leste do Tocantins. Rio de Janeiro: Consequência E ditora, 2015.

CARNEIRO DA CUNHA, M.; ALMEIDA, M. W. B. Populações Indígenas, Povos Tradicionais e Conservação na A mazônia. In: CA POBIAN CO, J. P. R. et al (org.) Biodiversidade na Amazônia Brasileira: Avaliação e Ações Prioritárias para a Conservação, Uso Sustentável e Repartição de Benefícios. São Paulo: Instituto Socioambiental e E stação L iberdade, 2001, p. 184-193.

CARVALHO, C. O Sertão. I mperatriz/ M aranhão: Ética, 2006.

CERTEAU, M. de. A escrita da história. Rio de Janeiro: Editora Forense, 1982.

CHIZZOTIi, A. A pesquisa qualitativa em ciências humanas e sociais: evolução e desafios. Revista Portuguesa de Educação. v.16, no 002. Braga, Portugal: U niver sidade do M inho, 2003.

DIEGUES, A. C. (org.). Os saberes tradicionais e a biodiversidade no Brasil. Brasília: Ministério do M eio Ambiente - MMA, 2000. Disponível em: http:/ / livroaberto.ibict.br/ bitstream Acesso em 15 de out de 2017

GOMES, A. L. de A.; FERnANDES, M. L. B. Sertão: lócus mediterraneus. In: CUNHA, L.; JACINTO, R. (coord.) Paisagens e dinâmicas territoriais em Portugal e Brasil: as novas geografias de língua portuguesa. Lisboa: Âncora E ditora, 2014, Coleção I berog rafias, no 26.

HAESBAERT, R. Desterritorialização: entre as redes e os aglomerados de exclusão. In: CAST RO, I. E. de; GOMES, P. C. da C.; CORRÊA, R. L. Geografia: Conceitos e Temas. Rio de Janeiro, Bertrand Brasil, 2009.

IBAM A, Instituto Brasileiro do M eio Ambiente e dos Recursos Naturais Renováveis; Projeto de diagnóstico socioeconômico-cultural-ambiental no Parque da Chapada das M esas- M A. M arques, A.R.; T chaicka, L. \& Lima, L.P., M aranhão, 2006. não publicado.

IPHAN. Patrimônio cultural imaterial para saber mais Brasília, D F, 2007.

LITTLE, P.E. Territórios sociais e povos tradicionais no Brasil: por uma antropologia da territorialidade. Ed UNB , Brasília, 2002. Disponível em: http:/ / www.dan.unb.br/images/ pdf/ anuario_antro pologico/Separatas\%202002 Acesso em 15 de out de 2017

MACHAD O, L.M. C. P. Paisagem Cultural, in KOZEL, S.,SILVA,J.C., GIL, S.F.F., Org Da percepção e cognição a representação: reconstruções teóricas da Geografia Cultural e Humanista São Paulo: Terceira Margem; Curitiba:NEER, 2007.

MALDONAD 0, C. 0 turismo rural comunitário na A mérica Latina: gênesis, características e políticas. In: BARTHOLO, R.; BURSZTYN, I.; SANSOLO, D. (org.). Turismo de Base Comunitária: diversidade de olhares e experiências brasileiras. Rio de Janeiro: Letra e I magem, 2009, p. 25-44. 
M M A / SBF - SN U C, Sistema N acional de U nidades de Conservação. Lei n 9.985,de18 de julho de 2000; decreto n 4.340, de 22 de agosto de 2002. 5 ed. aum. Brasília,2004. Disponível em <http:// www.planalto.gov.br> Acesso em 15 de out 2010.

MARQUES, A. R. et al. Abordagens sobre 0 território e a territorialidade das comunidades sertanejas do Cerrado da Chapada das M esas/ M A/ CAMPO-TERRITÓRIO: Revista de Geografia A grária, v. 9, № 19, 2014.

M ARQUES, A. R. (org.) As comunidades sertanejas da área de abrangência do parque nacional da chapada das mesas e a sua interação com o bioma cerrado: entre o cotidiano vivido e experienciado em suas dimensões socioculturais e ambientais. Relatório de pesquisa. São Luís: UEM A/FAPEM A, 2015. M imeo.

MARQUES, A. R.; AM ORIM, M. C. C. T. Saberes $G$ eográficos integrados aos estudos territoriais sob a ótica da implantação do Parque Nacional da Chapada das Mesas, sertão de Carolina/Ma. Revista Geo em questão, v. 07, no 02, p.: 100-117, 2014.

PORT O-GONÇALVES, C. W. (org.) Os cerrados vistos por seus povos: 0 agroextrativismo no cerrado. Goiânia-Go: Centro de Desenvolvimento Agroecológico do Cerrado. Projeto Rede de Agroflorestadoresno Cerrado, Biblioteca do CEDAC, 2008.

RIBEIRO, F. de P. Memórias dos Sertões M aranhenses. São Paulo: Siciliano, 2002

RIGONAT O, V. D. \& ALMEIDA, M. G.. A singularidade do cerrado: a interação das populações tradicionais com as fitofisionomias. VIII
EREGEO - Encontro Regional de G eografia. Goiás. 2003.

SANT OS, M . O espaço do cidadão. São Paulo: N obel, 1987.

SILVA, C. A.F. Fronteira agrícola capitalista e ordenamento territorial. In: SANTOS, M. et al, Territórios: ensaios sobre 0 ordenamento territorial. Rio de Janeiro: Lamparina, 2007.

TROVÃO, J. R. O Processo de Ocupação do Território M aranhense. Cadernos IMESC V. São Luís, 2008. 


\section{BETWEEN BACKLAND AND SAVANA: PARALLELISMS AND DISPARITIES}

ABSTRACT: THIS WORK DEALS WITH ASPECTS OF THE CULTURAL UNIVERSE OF THE POPULATIONS INHABITING THE SOUTHERN BACKLANDS OF THE STATE OF MARANHÃO AS WELL AS THEIR RELATIONSHIP WITH NATURE. IT PRESENTS THE SERTANEJO THAT MAKES ITS CONNECTION WITH THE WORLD THROUGH SMALL CROPS, EXTRACTION OF NATURAL RESOURCES OF THE CERRADO (SAVANA) AND THE CREATION OF CATTLE IN EXTENSIVE SYSTEMS. IT ANALYSES THE TERRITORIALITY PRINTED IN THE LANDSCAPE THROUGH CULTURE AND COEXISTENCE WITH THE ENVIRONMENT. THE SERTANEJO REVEALS ITSELF AS INSPIRATION FOR ANOTHER MODEL OF DEVELOPMENT, BASED ON THE RATIONAL USE OF RESOURCES. IT ADDRESSES THE AUTONOMY OF THESE PEOPLES WHO HAVE LIVED IN THIS REGION FOR MORE THAN A CENTURY. THIS IS A QUALITATIVE APPROACH RESEARCH. IT IS HOPED TO CONTRIBUTE WITH THE KNOWLEDGE AND THE VALORIZATION OF THIS CULTURE.

KEYWORDS: TERRITORY; TERRITORIALITYS; COUNTRY-CULTURE; SAVANA; BACKLAND.

\section{ENTRE EL SERTÓN Y EL CERRADO: PARALELISMOS Y DISPARIDADES}

RESUMEN: ESTE TRABAJO ABORDA ASPECTOS DEL UNIVERSO CULTURAL DE LAS POBLACIONES QUE HABITAN EL SERTÃO SUR DEL ESTADO DE MARANHÃO, ASÍ COMO SU RELACIÓN CON LA NATURALEZA. EL TEXTO PRESENTA EL SERTANEJO QUE REALIZA SU CONEXIÓN CON EL MUNDO POR MEDIO DE LA ROZA PARA SUBSISTENCIA, DE LA EXTRACCIÓN DE RECURSOS NATURALES DEL CERRADO Y DE LA CREACIÓN DE BUEY, SIENDO SU TERRITORIALIDAD IMPRESA EN EL PAISAJE POR MEDIO DE LA CULTURA Y DE LA CONVIVENCIA CON EL AMBIENTE. EL SERTANEJO SE REVELA COMO INSPIRACIÓN PARA OTRO MODELO DE DESARROLLO, PAUTADO EN EL USO RACIONAL DE LOS RECURSOS. ABORDA LA AUTONOMÍA DE ESOS PUEBLOS QUE VIVEN DESDE HACE MÁS DE UN SIGLO EN ESTA REGIÓN. SE TRATA DE UNA INVESTIGACIÓN DE ENFOQUE CUALITATIVO. SE ESPERA CONTRIBUIR CON EL CONOCIMIENTO Y LA VALORIZACIÓN DE ESA CULTURA.

PALABRAS CLAVE: TERRITORIO; TERRITORIALIDADES; CULTURA SERTANEJA; CERRADO; SERTÃO. 